\title{
Czochralski-Based Growth and Characteristics of Selected Novel Single Crystals for Optical Applications
}

\author{
K. ShimamurA ${ }^{a, b, *}$ And E.G. VÍllorA ${ }^{a}$ \\ ${ }^{a}$ National Institute for Materials Science, 1-1 Namiki, Tsukuba, 305-0044, Japan \\ ${ }^{b}$ Faculty of Science and Engineering, Waseda University, 3-4-1 Okubo, Shinjuku, 169-8555, Japan \\ In the Year of Professor Jan Czochralski, we with pleasure review the representative recent works of our group, \\ Optical Single Crystals Group, NIMS, Japan. Our group has been working on the development of novel single \\ crystals for optical applications based on the Czochralski technique. Here, 4 kinds of topics are reviewed. 1st one is \\ ferroelectric fluoride $\mathrm{BaMgF}_{4}$ single crystals for UV nonlinear optical applications including quasi-phase matching \\ device fabrications. 2nd one is transparent conductive $\beta-\mathrm{Ga}_{2} \mathrm{O}_{3}$ single crystals as semiconductor, which has large \\ band-gap, $4.8 \mathrm{eV}$, for LED applications. 3rd one is F-doped core-free $\mathrm{Y}_{3} \mathrm{Al}_{5} \mathrm{O}_{12}$ single crystals as a potential new \\ lens material for UV/VUV wavelength region. Last one is superior magneto-optical $\left\{\mathrm{Tb}_{3}\right\}\left[\mathrm{Sc}_{2-x} \mathrm{Lu}_{x}\right]\left(\mathrm{Al}_{3}\right) \mathrm{O}_{12}$ \\ single crystals for near infrared to visible region, and $\mathrm{CeF}_{3} / \mathrm{PrF}_{3}$ single crystals for UV region.
}

DOI: $10.12693 /$ APhysPolA.124.265

PACS: 81.10.St, 77.84.-s, 85.60.Jb, 42.79.Bh, 78.20.Ls, 85.70.Sq

\section{Introduction}

Recently, optical technology progress in a wide range of applications, and at the same time, still demands the further development. One of the key issue is to present new optical sources in UV/VUV wavelength region. Another one is to increase laser power. Since conventional crystal materials face some of the limitations, these issues require new optical single crystals.

From these view points, we have been working on the development of novel single crystals for the diverse optical applications. In this review, ferroelectric fluoride, $\beta$ - $\mathrm{Ga}_{2} \mathrm{O}_{3}$, F-doped core-free $\mathrm{Y}_{3} \mathrm{Al}_{5} \mathrm{O}_{12}$ and magneto-optical garnet single crystals including some of the additional topical crystals, which have advantageous characteristics toward the above demands, will be introduced as representative recent research subjects of our group (homepage of our group: www.nims.go.jp/group/oscg/ index_e.html).

The Czochralski technique is actually one of the most important and widely used technique among all the crystal growth techniques. Especially for industrial applications, Czochralski technique is remarkably precious one, which enables the large size and low cost crystal growth. Several famous crystal growth techniques are also derived from the Czochralski technique. For instance, Kyropoulos technique is used for sapphire growth. Liquid encapsulated Czochralski (LEC) technique enables the growth of volatile semiconductors such as GaAs and InP. Edge-defined, film-fed growth (EFG) technique is also developed to realize a shaped crystal growth. One of the most favorable characteristic of the Czochralski technique is that we can feel we are "growing" beautiful bulk single crystals. We can see all the growth process by our eyes, and when we change parameters, crystals show/reply to

*corresponding author; e-mail: SHIMAMURA.Kiyoshi@nims.go.jp us during growth at very high temperature. This is really a delicious flavor of the crystal growth. At the same time, nothing can be worse than to see grown crystals sank into the melt and disappear.

Since the Czochralski technique is successfull to satisfy both industrial severe requirements and happiness of crystal growers, we mainly work with this technique. At the same time, we use the derived technique from the Czochralski one, mostly EFG technique. In this article, some of our novel crystals grown by these techniques are reviewed with biggest pleasure inYear of Professor Jan Czochralski. If we could show the great importance of the Czochralski technique for the science and industry, that would be the ultimate happiness.

\section{Ferroelectric fluoride $\mathrm{BaMgF}_{4}$}

Excimer lasers are the currently used coherent light sources for UV/VUV wavelength region, namely, ArF $(193 \mathrm{~nm})$ and $\mathrm{KrF}(248 \mathrm{~nm})$. These present several disadvantages such as fast degradation, toxicity and low beam quality, and therefore alternative sources are strongly requested. All solid-state lasers (ASSL) emitting at short wavelengths are realized by second-, third- and fourth-harmonic generation using oxide nonlinear crystals such as $\beta-\mathrm{BaB}_{2} \mathrm{O}_{4}, \mathrm{CsLiB}_{6} \mathrm{O}_{10}, \mathrm{LiB}_{3} \mathrm{O}_{5}$, and $\mathrm{Li}_{2} \mathrm{~B}_{4} \mathrm{O}_{7}$, which can be birefringent phase matched [1], whereas the lack of optical grade nonlinear crystals transparent in the UV, as well as large Poynting-vector walk-off inherent to the birefringent phase matching at short wavelengths, have fundamentally made impossible the SHG in the UV/VUV. A new approach, the quasi-phase matching (QPM), which was theoretically predicted already in the 60 's [2], is being developed since the beginning of the 90 's [3]. By this method, the frequency conversion is obtained by the use of a ferroelectric crystal, which has been periodically poled (PP) in $\mu$ m order domains. SHG by QPM has been shown in well-known nonlinear crystals, such as $\mathrm{LiNbO}_{3}$ or $\mathrm{LiTaO}_{3}$ [4]. These crystals, however, cannot be used in the UV/VUV wavelength region, since 
their cutoff wavelengths lie in the near UV at 330 and $280 \mathrm{~nm}$, respectively.

Ferroelectricity has been shown by a pulsed-field technique on the pyroelectric fluoride $\mathrm{BaMF}_{4}$ family $(\mathrm{M}=\mathrm{Mg}, \mathrm{Mn}, \mathrm{Fe}, \mathrm{Co}, \mathrm{Ni}, \mathrm{Zn})$, except in the case of $\mathrm{M}=\mathrm{Mn}$ and $\mathrm{Fe}$ [5]. Among these, $\mathrm{BaMgF}_{4}$ is attracting much attention since it is transparent in the UV/VUV $[6,7]$, with a decreasing transparency towards the cutoff wavelength at approximately $130 \mathrm{~nm}$. The origin of the optical losses in the UV/VUV has not been cleared yet, but a correlation with the concentration of scattering centers in the VIS has been observed [7]. $\mathrm{BaMgF}_{4}$ has been studied as a host crystal doped with transition metal and rare earth for ASSL applications [8, 9]. Further, thin films of $\mathrm{BaMgF}_{4}$ have been investigated for memory applications, namely metal-ferroelectric-semiconductor field-effect transistors [10, 11]. The ferroelectric properties, however, are not established yet; Eibschuetz et al. [5] obtained the reversal of the spontaneous polarization $\left(7.7 \mu \mathrm{C} / \mathrm{cm}^{2}\right)$ at electric fields in the order of $50 \mathrm{kV} / \mathrm{cm}$, while the hysteresis loop measured on a thinned sample $(10 \mu \mathrm{m})$ by Sinharoy et al. [11] indicated $8.5 \mu \mathrm{C} / \mathrm{cm}^{2}$ and $95.4 \mathrm{kV} / \mathrm{cm}$ for the spontaneous polarization and the coercive field, respectively.

We have selected $\mathrm{BaMgF}_{4}$ as the most promising material for UV/VUV SHG-QPM after several material search [7, 12-14]. Then, we have grown large size single crystals of $\mathrm{BaMgF}_{4}$, and determined the ferroelectric properties of bulk single-crystals by the measurement of the polarization hysteresis. The coercive field was analyzed as a function of the applied frequency and used for the periodical poling of $\mu \mathrm{m}$ order ferroelectric domains. The selective etching of ferroelectric domains on a PP $c$-plane plate was examined. Further, SHG emission in different wavelength was demonstrated.

Crystal growth was carried out by the Czochralski $(\mathrm{Cz})$ technique with a $30 \mathrm{~kW}$ RF-generator. High purity powders $\left(>99.99 \%\right.$ ) of commercially available $\mathrm{BaF}_{2}$ and $\mathrm{MgF}_{2}$ powders were weighted and mixed in stoichiometric composition. $\mathrm{CF}_{4}$ gas $(>99.999 \%$ ) was flowed into the furnace and the powders were melted at approximately $920^{\circ} \mathrm{C}[15]$. An oriented $\mathrm{BaMgF}_{4}$ single crystal was used as a seed. The crystal rotation and pulling rate were fixed at $10 \mathrm{rpm}$ and $1 \mathrm{~mm} / \mathrm{h}$, respectively. A detailed description of the growth characteristics is reported elsewhere [7]. Figures 1 and 2 are examples we have grown by the same technique [16].

Ferroelectric hysteresis loops were measured with an FCE-1 equipment from Toyo Corporation. The voltage was applied in triangle wave form at frequencies varying between 0.05 and $100 \mathrm{~Hz}$. The $c$-oriented plate had a thickness of $0.5 \mathrm{~mm}$ and a gold electrode area of $10.4 \mathrm{~mm}^{2}$. Selectively etched domains were observed with an Olympus BX51 microscope.

As fundamental laser sources for the testing of the $\mathrm{PP}-\mathrm{BaMgF}_{4}$ frequency converters, we used (a) a pulsed $\mathrm{Nd}: \mathrm{Y}_{3} \mathrm{Al}_{5} \mathrm{O}_{12}$ (YAG) laser YAG 5000 series from B.M. Industries Co., Ltd (10 ns pulse width at a repetition

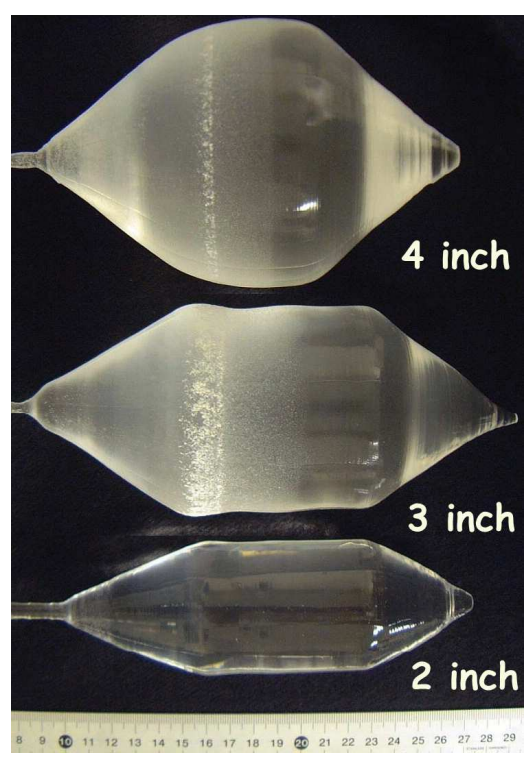

Fig. 1. Ce-doped $\mathrm{LiCaAlF}_{6}$ single crystals grown by the Czochralski technique for VUV laser applications.

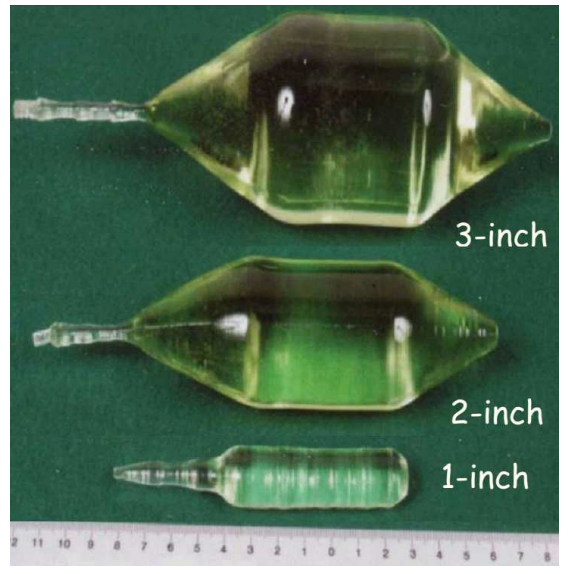

Fig. 2. Tm and Ho co-doped $\mathrm{LiLuF}_{4}$ single crystals grown by the Czochralski technique for IR laser applications.

rate of $10 \mathrm{~Hz}$ ), (b) a pulsed Ti:sapphire Mira Optima 900-P from Coherent (3 ps pulse width at a repetition rate of $76 \mathrm{MHz}$ ), and (c) a master oscillator power amplifier (MOPA) from Spectra physics (7 ns pulse width at a repetition rate of $10 \mathrm{~Hz}$ ).

Figure 3 shows $\mathrm{BaMgF}_{4}$ single crystal with 2 inch in diameter without cracks [17]. Precise control of a diameter, especially to extend a diameter slowly at the shoulder part was fundamentally important. Otherwise, large crack formations frequently occurred. The growth of 2 inch size crystals are required to fabricate QPM devices.

Three representative polarization hysteresis loops are shown in Fig. 4. The loops are very symmetric, exhibiting a close to ideal shape with a loop squareness 


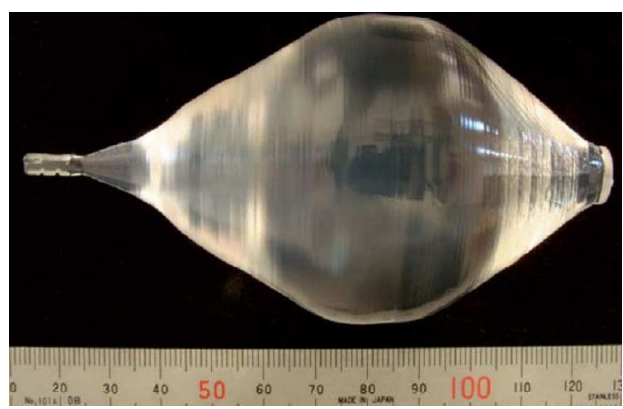

Fig. 3. 2 inch size $\mathrm{BaMgF}_{4}$ single crystal grown by the Czochralski technique.

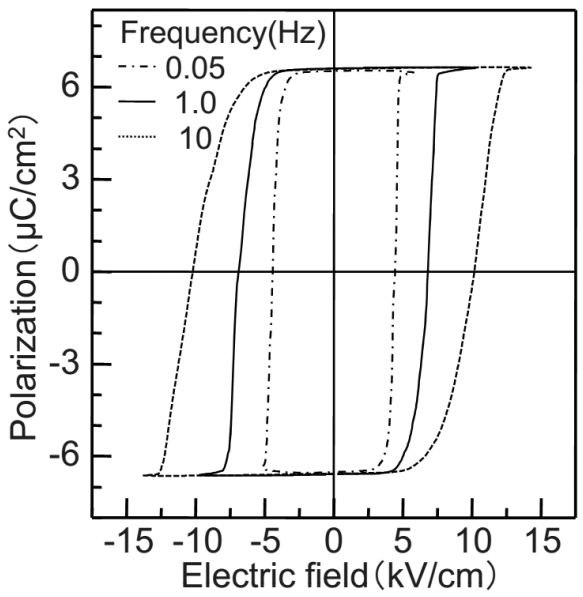

Fig. 4. Polarization hysteresis loop of $\mathrm{BaMgF}_{4}$.

over $99 \%$ (calculated as the ratio between the remanence and the spontaneous polarization, $\left.P_{\mathrm{r}} / P_{\mathrm{s}}\right)$. Ferroelectric properties obtained from these loops are summarized in Table. The spontaneous polarization, with a value of $6.6 \mu \mathrm{C} / \mathrm{cm}^{2}$, is lower than the reported ones $[5,11]$ and about a third of $\mathrm{KTiOPO}_{4}$. On the other hand, the coercive field varies between 4 and $24 \mathrm{kV} / \mathrm{cm}$ [13].

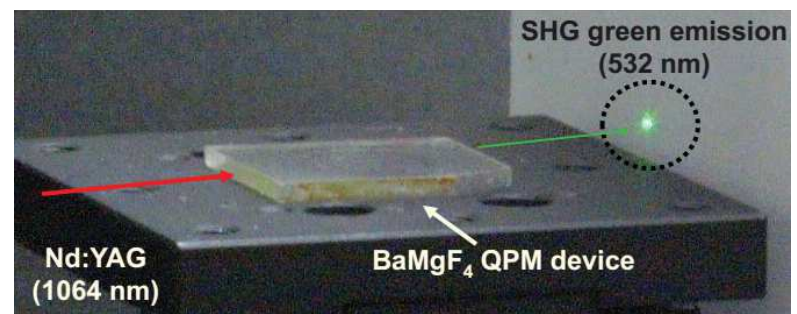

Fig. 5. Green SHG from IR using a BMF-QPM device.

As-grown crystals are found to be single domain for the most part. The polarization reversal is induced by an electric field through the displacement of the Ba atoms along the $c$ axis and the rotation of the Mg-F6 octahedra around the $\mathrm{Mg}$ atoms. The theoretically predicted matching conditions for SHG QPM have been
TABLE

Ferroelectric properties obtained from the hysteresis loops of $\mathrm{BaMgF}_{4}$ as a function of the frequency.

\begin{tabular}{l|c|c|c|c}
\hline \hline \multicolumn{1}{c|}{ Frequency } & $\nu[\mathrm{Hz}]$ & 0.05 & 1.0 & 10 \\
\hline maximum applied field & $E_{\max }[\mathrm{V}]$ & 275 & 500 & 700 \\
coercive field & $E_{\mathrm{c}}[\mathrm{kV} / \mathrm{cm}]$ & 4.4 & 6.8 & 10.2 \\
spontaneous polarization & $P_{\mathrm{S}}\left[\mu \mathrm{C} / \mathrm{cm}^{2}\right]$ & 6.53 & 6.63 & 6.63 \\
remanence polarization & $P_{\mathrm{r}}\left[\mu \mathrm{C} / \mathrm{cm}^{2}\right]$ & 6.52 & 6.60 & 6.58 \\
loop squareness & $P_{\mathrm{r}} / P_{\mathrm{S}}[\%]$ & 99.8 & 99.5 & 99.2 \\
resistance & $R[\mathrm{M} \Omega \mathrm{cm}]$ & 842 & 93 & 15
\end{tabular}

tested. Devices with different periods have been processed and checked. With an initial period of $70 \mu \mathrm{m}$ we succeeded in frequency-doubling the emission from a $1064 \mathrm{~nm} \mathrm{Nd}$ :YAG laser using the $d_{33}$ nonlinear coefficient. A photograph of the emitting device is shown in Fig. 5.

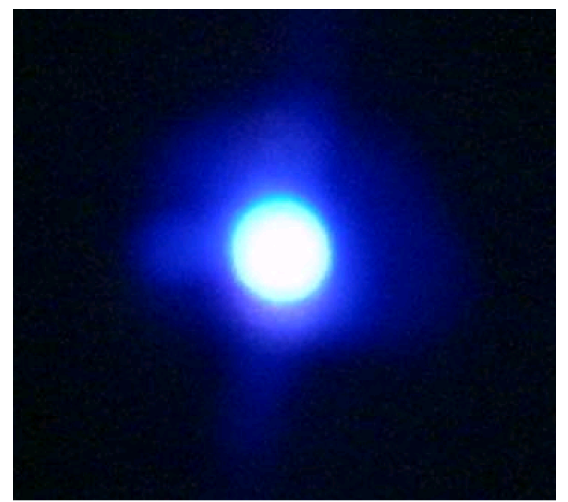

Fig. 6. $396 \mathrm{~nm}$ SHG using a BMF-QPM device.

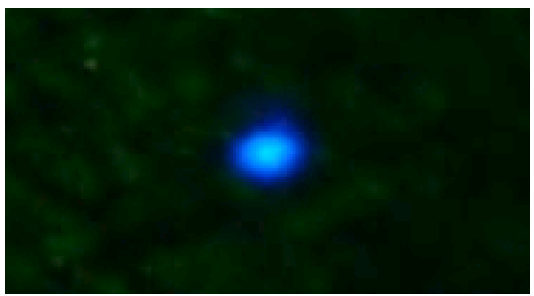

Fig. 7. $277 \mathrm{~nm}$ SHG using a BMF-QPM device.

As a next step we reduced the period to match the tunable range of a Ti:sapphire laser. Periods between 24 and $40 \mu \mathrm{m}$ were used to obtain SHG in the VIS and near-UV wavelength regions. The photograph of Fig. 6 shows as an example the $396 \mathrm{~nm}$ SHG visualized on a phosphorescent paper. Subsequently, $368 \mathrm{~nm}$ SHG, which is close to the limit of the pulsed Ti:sapphire laser, was also obtained.

The shortest emission obtained so far is $277 \mathrm{~nm}$ from $554 \mathrm{~nm}$ laser of MOPA as fundamental source, shown in Fig. 7 [18]. In order to achieve emission at shorter wavelengths similar to those of the gas excimer lasers, the grating period needs to be considerably shortened. The realization of these periods gets towards the limit of 


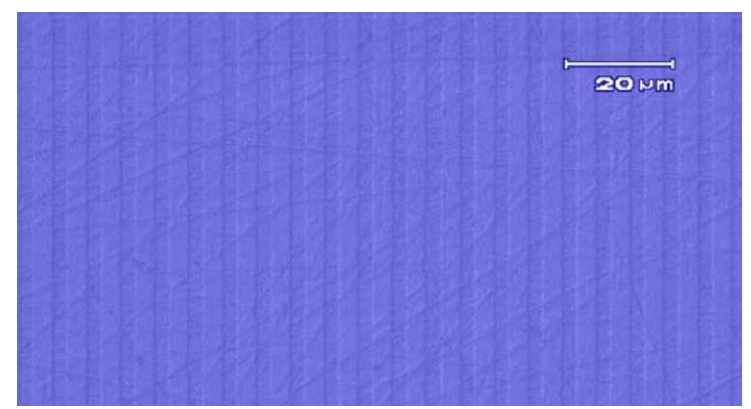

Fig. 8. Periodically poled $\mathrm{BaMgF}_{4} c$-plate.

standard photolithographical processes, which use contact masks and a minimum pitch of approximately $1 \mu \mathrm{m}$.

The shortest period achieved so far is shown in Fig. 8. This photograph shows a $c$-cut $\mathrm{BaMgF}_{4}$ sample after the poling process. The ferroelectric domain structure is visualized by a selective etching process of $+c$ and $-c$ surfaces. The obtained period is $6.6 \mu \mathrm{m}$, just about double of the one necessary for $193 \mathrm{~nm}$ emission.

\section{Substrate single crystal $\beta-\mathrm{Ga}_{2} \mathrm{O}_{3}$}

Although heteroepitaxial growth of gallium nitride compounds on sapphire is well established, sapphire does not represent an adequate candidate because of its insulating character. $\mathrm{SiC}$ is at present the most used conductive substrate for the growth of gallium nitrides [19]. However, due to the lack of transparency in the blue wavelength region, optical losses have to be taken into account for the design of LEDs. The search for alternative substrates has been pursued intensively [20], and it is still a remaining issue.

$\beta-\mathrm{Ga}_{2} \mathrm{O}_{3}$ belongs to the group of the transparent conductive oxides (TCOs). It exhibits the largest band gap among them, $E_{\mathrm{g}}=4.8 \mathrm{eV}(260 \mathrm{~nm})$ [21], and thus a unique transparency from the VIS into the UV region. This is an important property for the future generations of optoelectronic devices operating at shorter wavelengths. Due to the high transparency in the VIS wavelength region and the $n$-type conductivity, $\beta-\mathrm{Ga}_{2} \mathrm{O}_{3}$ is a new substrate candidate for the growth of gallium nitrides. The crystal structure of $\beta-\mathrm{Ga}_{2} \mathrm{O}_{3}$ has the monoclinic symmetry, with space group $C 2 / m$ [22], lattice parameters $a=12.23 \AA, b=3.04 \AA, c=5.80 \AA$ and $\beta=103.7^{\circ}$.

$\beta-\mathrm{Ga}_{2} \mathrm{O}_{3}$ is the only stable modification at high temperature, which remains stable upon cooling. Here, the stable crystal growth of $\beta-\mathrm{Ga}_{2} \mathrm{O}_{3}$, which is indispensable to achieve large size single crystals, was analyzed. By this approach, wafers of 2 inches in diameter $\beta-\mathrm{Ga}_{2} \mathrm{O}_{3}$ single crystals were obtained. Subsequently, the possibility to use $\beta-\mathrm{Ga}_{2} \mathrm{O}_{3}$ as a substrate for the epitaxial growth of $\mathrm{GaN}$ was examined. The blue emission from an InGaN multi-quantum-well (MQW) deposited on a $\beta-\mathrm{Ga}_{2} \mathrm{O}_{3}$ substrate and with vertical current injection was demonstrated.

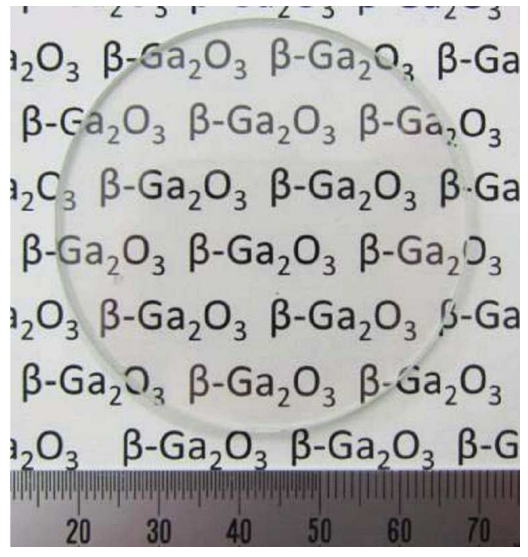

Fig. 9. Polished 2 inch size $\beta-\mathrm{Ga}_{2} \mathrm{O}_{3}$ single crystal wafer, presented by Koha Co., Ltd.

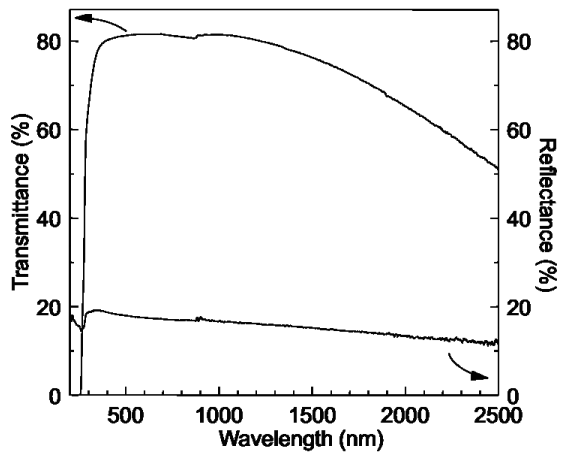

Fig. 10. Transmittance and reflectance of a $0.5 \mathrm{~mm}$ $\beta-\mathrm{Ga}_{2} \mathrm{O}_{3}$ wafer.

The EFG technique, which is one of the most important derivative of the $\mathrm{Cz}$ technique, was a successful one for the growth of large size $\beta-\mathrm{Ga}_{2} \mathrm{O}_{3}$ single crystals. Figure 9 shows a $\beta-\mathrm{Ga}_{2} \mathrm{O}_{3}$ single crystal with 2 inch size grown by the EFG technique. The crystal shown in Fig. 9 was obtained by the both side polishing [17]. Presented achievements are noteworthy since they show for the first time the way how to grow large size single crystals, as well as the capability to cut them in wafers, in spite of the remarkable cleavage nature of $\beta-\mathrm{Ga}_{2} \mathrm{O}_{3}$.

The wafers were highly transparent in the VIS wavelength region. The transmittance and reflectance spectra of a both sides polished wafer without antireflection coating are shown in Fig. 10 [23]. Scattering and absorption losses in the VIS wavelength region are negligibly small and the increasing absorption in the near infrared (IR) wavelength region is well known for TCOs, and indicates the presence of free carriers.

The electrical conductivity is shown as a function of the Si concentration in the double logarithmic plot of Fig. 11. The conductivity continuously increases by over three orders of magnitude, from a value as low as $0.03 \Omega^{-1} \mathrm{~cm}^{-1}$ for $6 \mathrm{~N}$-purity crystals to $50 \Omega^{-1} \mathrm{~cm}^{-1}$ for crystals with a high $\mathrm{Si}$ concentration. The $\mathrm{Si}$ incorporation saturates at about $0.2 \mathrm{~mol} \%$ when second-phase segregation appears [24-26]. 


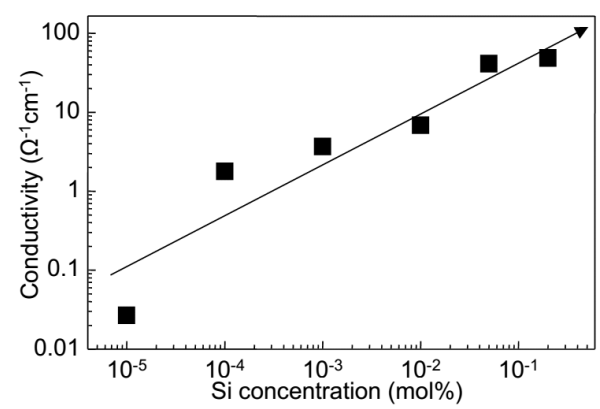

Fig. 11. Electrical conductivity of $\beta-\mathrm{Ga}_{2} \mathrm{O}_{3}$ as a function of the nominal $\mathrm{Si}$ concentration. The arrow indicates a systematical increase.

In addition to the high transparency and electrical conductivity, $\beta-\mathrm{Ga}_{2} \mathrm{O}_{3}$ exhibits an extraordinary high resistance to chemical agents, as well as mechanical hardness and stability at high temperature. All these properties make $\beta-\mathrm{Ga}_{2} \mathrm{O}_{3}$ an attractive substrate candidate for semiconductor materials.

(100) $\beta-\mathrm{Ga}_{2} \mathrm{O}_{3}$ substrates were used for the $\mathrm{GaN}$ deposition. GaN growth took place at 100 Torr by the metalorganic vapor phase epitaxy (MOVPE) technique. Low pressure processes, so-called LP-MOVPE, are widely used for the growth of conventional III-V compounds. Trimethyl-gallium (TMG) and $\mathrm{NH}_{3}$ were used as the source gases. The flow rate of $\mathrm{NH}_{3}$ was $1200 \mathrm{sccm}$. The deposition was done in two steps: firstly a low temperature (LT) GaN buffer layer was deposited at $600^{\circ} \mathrm{C}$, subsequently a GaN layer of $1000 \mathrm{~nm}$ was grown at $1070^{\circ} \mathrm{C}$.

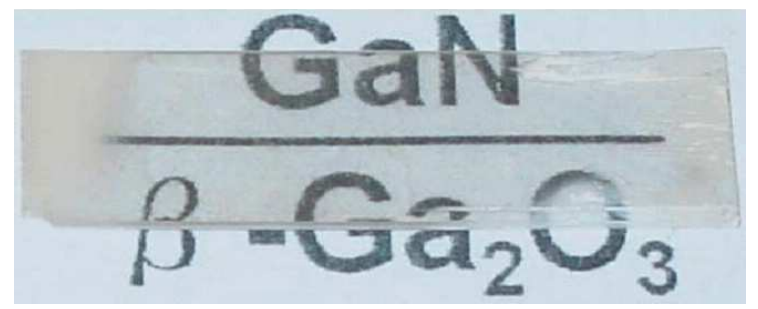

Fig. 12. Outlook of InGaN-MQW grown on $\beta-\mathrm{Ga}_{2} \mathrm{O}_{3}$.

A single GaN layer was deposited on an un-doped buffer layer. The GaN layer grown on the $\beta-\mathrm{Ga}_{2} \mathrm{O}_{3}$ substrate exhibits a very flat surface. After the successful deposition of a single GaN epi-layer, we proceeded with the fabrication of LED with vertical current injection. In order to enable the current flow between the substrate and the GaN layers, the $n$-type buffer layer doped with $\mathrm{Si}$ was employed by flowing $\mathrm{SiH}_{4}$ as source gas. The surface morphology of a GaN epilayer grown on a conductive buffer layer was unchanged. Next, a $\operatorname{In}_{0.12} \mathrm{GaN} /$ $\mathrm{In}_{0.03} \mathrm{GaN}$ MQW was deposited on the GaN layer, followed by a $p$-GaN layer. Figure 12 shows a top view of the deposited substrate [27]. It is seen that transparent InGaN-MQW epilayers have been deposited on the transparent $\beta-\mathrm{Ga}_{2} \mathrm{O}_{3}$ substrate. $p$ - and $n$-electrodes were deposited on the epilayers and the rear side of the substrate, respectively. Blue emission was obtained after the vertical current injection with a current of $30 \mathrm{~mA}$. Higher light yield with higher electric current was also obtained. Based on these investigations, several types of packaged InGaN-MQW $/ \beta-\mathrm{Ga}_{2} \mathrm{O}_{3}$ LEDs have been successfully obtained.

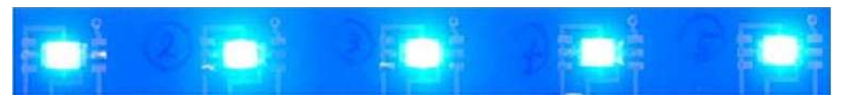

Fig. 13. Blue emission from InGaN-MQW $/ \beta-\mathrm{Ga}_{2} \mathrm{O}_{3}$ SMD-type LEDs.

Figure 13 shows SMD type LEDs. Although the electrical properties of the buffer layer, as well as the energy band alignment to the substrate are a matter of future investigations, present results demonstrate the successful LED fabrication on the $\beta-\mathrm{Ga}_{2} \mathrm{O}_{3}$ substrate.

\section{Lens material F-doped core-free $\mathrm{Y}_{3} \mathrm{Al}_{5} \mathrm{O}_{12}$}

Industrial semiconductor related facilities such as next generation optical lithography and optical related facilities such as microscope and digital camera, require new types of UV/VUV optical lens materials. Typical required characteristics are high transparency, different wavelength dispersion of refractive indices, uniformity of refractive index, and low cost. However, materials which can satisfy these requirements are limited.

Recently, $\mathrm{Lu}_{3} \mathrm{Al}_{5} \mathrm{O}_{12}$ has been reported as a potential candidate for this. Although $\mathrm{Lu}_{3} \mathrm{Al}_{5} \mathrm{O}_{12}$ may have potential high transmittance at UV/VUV and large refractive, 2.1435 , several serious problems have been pointed out, such as practical low transmittance, difficulty to grow high quality and uniform crystals leading to the high inhomogeneity of refractive index.

In this work, we have developed F-doped core-free $\mathrm{Y}_{3} \mathrm{Al}_{5} \mathrm{O}_{12}$ single crystals, by re-examining the standard $\mathrm{Y}_{3} \mathrm{Al}_{5} \mathrm{O}_{12}$ single crystals [17].

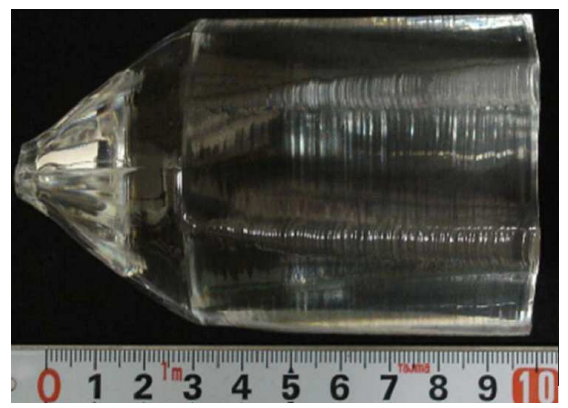

Fig. 14. 2 inch size F-doped core-free $\mathrm{Y}_{3} \mathrm{Al}_{5} \mathrm{O}_{12}$ single crystal, presented by Dai-Ichi Dentsu Ltd.

Figure 14 shows 2 inch size F-doped core-free $\mathrm{Y}_{3} \mathrm{Al}_{5} \mathrm{O}_{12}$ single crystal, grown by the $\mathrm{Cz}$ technique. Core-free nature was confirmed by the polarizing microscope observation of the vertically sliced wafers toward 


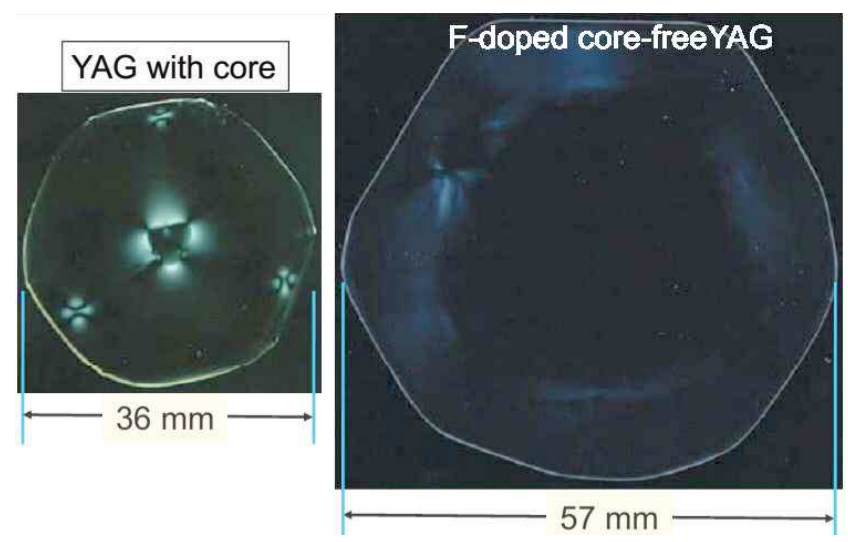

Fig. 15. Polarizing microscope photos of core-free $\mathrm{Y}_{3} \mathrm{Al}_{5} \mathrm{O}_{12}$ (Fig. 14) and standard $\mathrm{Y}_{3} \mathrm{Al}_{5} \mathrm{O}_{12}$.

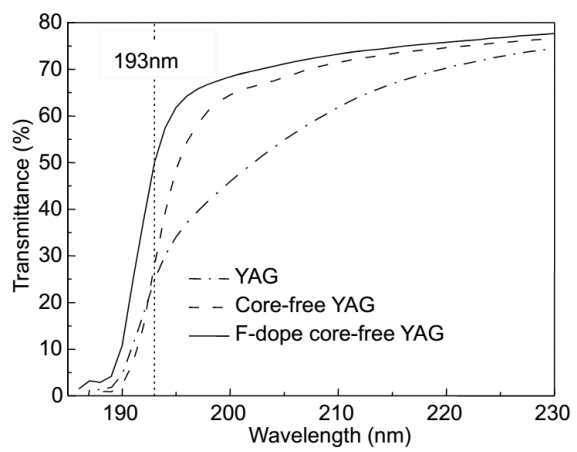

Fig. 16. Transmission spectra of different type of $\mathrm{Y}_{3} \mathrm{Al}_{5} \mathrm{O}_{12}$ single crystals.

the growth axis (Fig. 15). This realizes the high uniformity of refractive index distribution. The improvement of transmittance, especially at $\mathrm{UV} / \mathrm{VUV}$, was revealed by F-doing into $\mathrm{Y}_{3} \mathrm{Al}_{5} \mathrm{O}_{12}$ single crystal (Fig. 16). Additionally, this F-doped core-free $\mathrm{Y}_{3} \mathrm{Al}_{5} \mathrm{O}_{12}$ crystal has shown quite large refractive index, 2.145, which is even slightly larger than that of $\mathrm{Lu}_{3} \mathrm{Al}_{5} \mathrm{O}_{12}$ (Fig. 17).

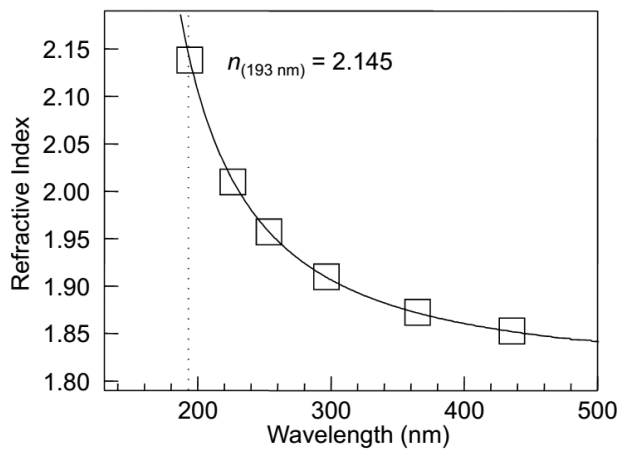

Fig. 17. Precisely measured refractive indices of $\mathrm{Y}_{3} \mathrm{Al}_{5} \mathrm{O}_{12}$ single crystal.

\section{Faraday rotator $\left\{\mathrm{Tb}_{3}\right\}\left[\mathrm{Sc}_{2-x} \mathrm{Lu}_{x}\right]\left(\mathrm{Al}_{3}\right) \mathrm{O}_{12}$}

Optical isolators (OIs) are fundamental components for optical communications, high-power fiber-laser machinery and others. OIs prevent from optical feedback, which causes parasitic oscillations in amplifier systems or frequency instabilities in laser diodes. The central part of an OI is a Faraday crystal, which rotates the polarization plane of the laser beam. $\mathrm{Y}_{3} \mathrm{Fe}_{5} \mathrm{O}_{12}$ (YIG) is so far the most commonly used crystal in OIs. It is characterized by a high transparency in the IR region, a large Faraday rotation angle, and a low saturation magnetization. However, $\mathrm{Y}_{3} \mathrm{Fe}_{5} \mathrm{O}_{12}$ cannot be used at shorter wavelengths $(<1100 \mathrm{~nm})$ due to its poor transparency. Taking advantage of the magneto-optical (MO) properties of $\mathrm{Tb}^{3+}$ ions, optically isotropic terbium-garnets are the material systems considered for wavelengths below $1100 \mathrm{~nm}$. $\mathrm{Tb}_{3} \mathrm{Al}_{5} \mathrm{O}_{12}$ (TAG) has been reported to show resonable properties as the Faraday rotator (FR) [28, 29], however, its incongruent melting nature makes impossible the growth of large crystals [30]. Instead, $\mathrm{Tb}_{3} \mathrm{Ga}_{5} \mathrm{O}_{12}$ (TGG) [31] is industrially grown by the $\mathrm{Cz}$ technique to fabricate OIs. Although it melts congruently at approximately $1825^{\circ} \mathrm{C}$, its growth is not exempt of difficulties [32].

We have designed a new garnet single crystal, $\left\{\mathrm{Tb}_{3}\right\}\left[\mathrm{Sc}_{2-x} \mathrm{Lu}_{x}\right]\left(\mathrm{Al}_{3}\right) \mathrm{O}_{12}$ (TSLAG), by the substitution of $\mathrm{Al}^{3+}$ of $\mathrm{Tb}_{3} \mathrm{Al}_{5} \mathrm{O}_{12}$ in the octahedral site with a proper mixture of $\mathrm{Sc}_{2-x} \mathrm{Lu}_{x}$ which can stabilize the garnet structure adjusting the average cationic size [33]. A detailed analysis of the optical and MO properties of $\left\{\mathrm{Tb}_{3}\right\}\left[\mathrm{Sc}_{2-x} \mathrm{Lu}_{x}\right]\left(\mathrm{Al}_{3}\right) \mathrm{O}_{12}$ crystals is carried out [34].

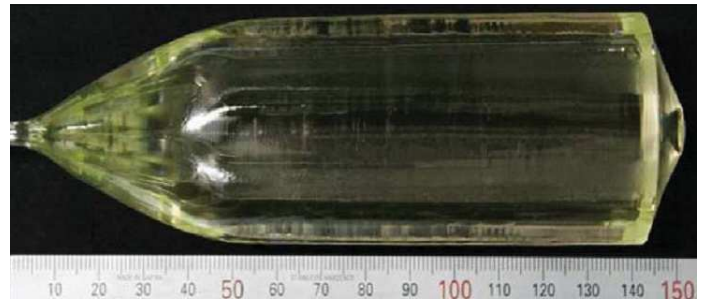

Fig. 18. 2 inch size $\left\{\mathrm{Tb}_{3}\right\}\left[\mathrm{Sc}_{2-x} \mathrm{Lu}_{x}\right]\left(\mathrm{Al}_{3}\right) \mathrm{O}_{12}$ single crystal grown by the Czochralski technique, presented by Fujikura Ltd.

Nominal TSLAG single crystals with $x=0.05$ were grown by the $\mathrm{Cz}$ technique. As starting materials commercial oxides of $\mathrm{Tb}_{4} \mathrm{O}_{7}, \mathrm{Sc}_{2} \mathrm{O}_{3}, \mathrm{Lu}_{2} \mathrm{O}_{3}$, and $\mathrm{Al}_{2} \mathrm{O}_{3}$ of $4 \mathrm{~N}$ purity were used. These were weighted in the corresponding nominal cationic ratios. Mixed powders were charged in an Ir crucible and molten with a $30 \mathrm{~kW}$ RF generator. Figure 18 shows the representative 2 inch size $\left\{\mathrm{Tb}_{3}\right\}\left[\mathrm{Sc}_{2-x} \mathrm{Lu}_{x}\right]\left(\mathrm{Al}_{3}\right) \mathrm{O}_{12}$ single crystal. The pulling and rotation rates were fixed to $0.5 \mathrm{~mm} / \mathrm{h}$ and $10 \mathrm{rpm}$, respectively. The $\mathrm{Tb}_{3} \mathrm{Ga}_{5} \mathrm{O}_{12}$ single crystal reference was purchased from Furuuchi Chemical Corporation.

Figure 19 shows the absorption coefficient, $\alpha$, as a function of the wavelength obtained from the transmittance 


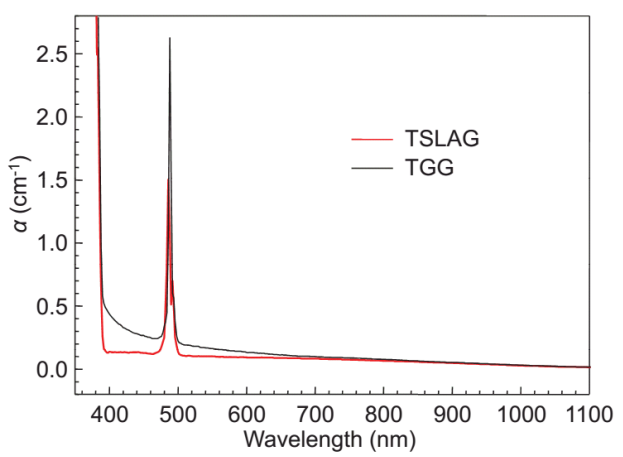

Fig. 19. Absorption coefficient of $\left\{\mathrm{Tb}_{3}\right\}\left[\mathrm{Sc}_{2-x} \mathrm{Lu}_{x}\right]\left(\mathrm{Al}_{3}\right) \mathrm{O}_{12}$ and $\mathrm{Tb}_{3} \mathrm{Ga}_{5} \mathrm{O}_{12}$ crystals.

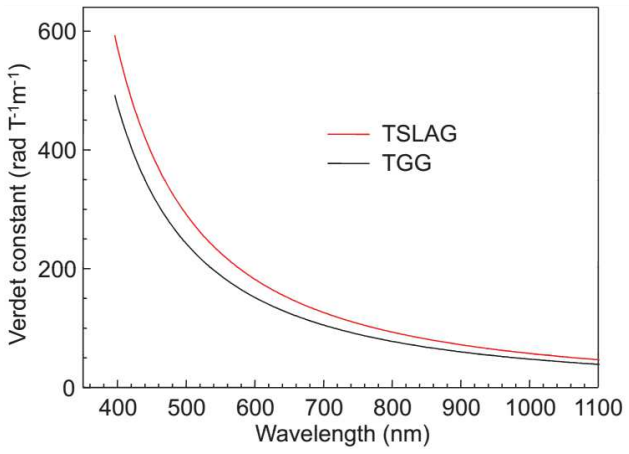

Fig. 20. Verdet constant of $\left\{\mathrm{Tb}_{3}\right\}\left[\mathrm{Sc}_{2-x} \mathrm{Lu}_{x}\right]\left(\mathrm{Al}_{3}\right) \mathrm{O}_{12}$ in comparison with $\mathrm{Tb}_{3} \mathrm{Ga}_{5} \mathrm{O}_{12}$.

and reflectance spectra for $\left\{\mathrm{Tb}_{3}\right\}\left[\mathrm{Sc}_{2-x} \mathrm{Lu}_{x}\right]\left(\mathrm{Al}_{3}\right) \mathrm{O}_{12}$ and $\mathrm{Tb}_{3} \mathrm{Ga}_{5} \mathrm{O}_{12}$. In both compounds, the $\mathrm{Tb}^{3+}{ }^{7} F_{6} \rightarrow$ ${ }^{5} D_{3},{ }^{5} D_{2}$ absorption bands start below $390 \mathrm{~nm}$ and the transition ${ }^{7} F_{6} \rightarrow{ }^{5} D_{4}$ lies at about $488 \mathrm{~nm}$. Both crystals are practically transparent in the near IR region, however, it is noteworthy the continuous increase in absorbance observed in $\mathrm{Tb}_{3} \mathrm{Ga}_{5} \mathrm{O}_{12}$ from the IR to shorter wavelengths. This feature contrasts with the low absorption of $\left\{\mathrm{Tb}_{3}\right\}\left[\mathrm{Sc}_{2-x} \mathrm{Lu}_{x}\right]\left(\mathrm{Al}_{3}\right) \mathrm{O}_{12}$ in the whole VIS-IR.

The results of the Faraday rotation angle measurements are displayed in Fig. 20. The Verdet constant $(V)$ dispersion of $\left\{\mathrm{Tb}_{3}\right\}\left[\mathrm{Sc}_{2-x} \mathrm{Lu}_{x}\right]\left(\mathrm{Al}_{3}\right) \mathrm{O}_{12}$ is shown in comparison with that of $\mathrm{Tb}_{3} \mathrm{Ga}_{5} \mathrm{O}_{12}$. It is seen that $\left\{\mathrm{Tb}_{3}\right\}\left[\mathrm{Sc}_{2-x} \mathrm{Lu}_{x}\right]\left(\mathrm{Al}_{3}\right) \mathrm{O}_{12}$ possesses a higher $V$ value, with an increment of $20 \%$ independently of the considered wavelength.

After the precise determination of $\alpha$ and $V$, the MO figure of merit (FM), defined as $V / \alpha$, has been estimated and is plotted in Fig. 21. It is seen that the FM of $\left\{\mathrm{Tb}_{3}\right\}\left[\mathrm{Sc}_{2-x} \mathrm{Lu}_{x}\right]\left(\mathrm{Al}_{3}\right) \mathrm{O}_{12}$ is larger than that of $\mathrm{Tb}_{3} \mathrm{Ga}_{5} \mathrm{O}_{12}$ at all wavelengths. In the near IR region this is mainly attributed to the higher $V$ value, while in the VIS also the higher transparency of $\left\{\mathrm{Tb}_{3}\right\}\left[\mathrm{Sc}_{2-x} \mathrm{Lu}_{x}\right]\left(\mathrm{Al}_{3}\right) \mathrm{O}_{12}$ contributes to the remarkably higher FM of $\left\{\mathrm{Tb}_{3}\right\}\left[\mathrm{Sc}_{2-x} \mathrm{Lu}_{x}\right]\left(\mathrm{Al}_{3}\right) \mathrm{O}_{12}$ with respect to $\mathrm{Tb}_{3} \mathrm{Ga}_{5} \mathrm{O}_{12}$.

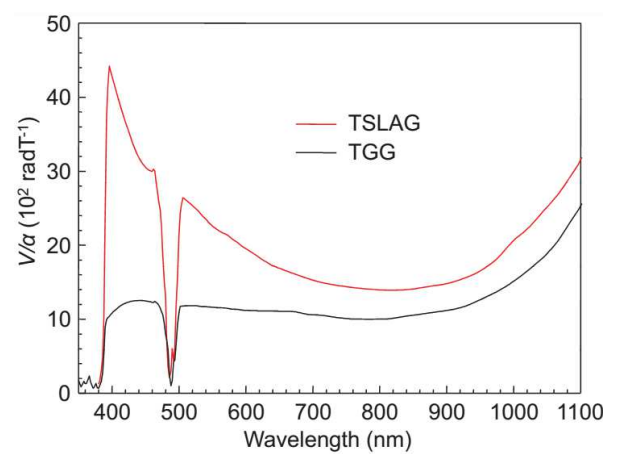

Fig. 21. Figure of merit of $\left\{\mathrm{Tb}_{3}\right\}\left[\mathrm{Sc}_{2-x} \mathrm{Lu}_{x}\right]\left(\mathrm{Al}_{3}\right) \mathrm{O}_{12}$ and $\mathrm{Tb}_{3} \mathrm{Ga}_{5} \mathrm{O}_{12}$.
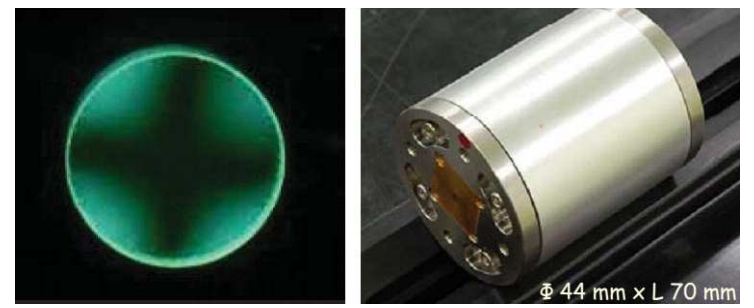

Fig. 22. (Left) $\left\{\mathrm{Tb}_{3}\right\}\left[\mathrm{Sc}_{2-x} \mathrm{Lu}_{x}\right]\left(\mathrm{Al}_{3}\right) \mathrm{O}_{12} \quad$ under crossed polarizers. (Right) A prototype of $\left\{\mathrm{Tb}_{3}\right\}\left[\mathrm{Sc}_{2-x} \mathrm{Lu}_{x}\right]\left(\mathrm{Al}_{3}\right) \mathrm{O}_{12}$-based optical isolator.

In order to check the potential substitution of $\mathrm{Tb}_{3} \mathrm{Ga}_{5} \mathrm{O}_{12}$ by $\left\{\mathrm{Tb}_{3}\right\}\left[\mathrm{Sc}_{2-x} \mathrm{Lu}_{x}\right]\left(\mathrm{Al}_{3}\right) \mathrm{O}_{12}$, the optical quality of the crystals was further analyzed. The photograph of a $10 \mathrm{~mm}$ long sample with $3 \mathrm{~mm}$ in diameter under crossed polarizers is shown in Fig. 22 (left). It is seen that the crystal is very homogeneous, free from scattering, defects, and twinning. Antireflection coatings were deposited on three crystals, and their extinction ratios were measured. The values obtained for all crystals were over the highest value of $\mathrm{Tb}_{3} \mathrm{Ga}_{5} \mathrm{O}_{12}(40 \mathrm{~dB})$, ranging between 41 and $47 \mathrm{~dB}$. Using one of these crystals, a first $\left\{\mathrm{Tb}_{3}\right\}\left[\mathrm{Sc}_{2-x} \mathrm{Lu}_{x}\right]\left(\mathrm{Al}_{3}\right) \mathrm{O}_{12}$-based prototype was assembled with the standard optics for a polarization independent $\mathrm{Tb}_{3} \mathrm{Ga}_{5} \mathrm{O}_{12}$-based OI (Fig. 22 (right)). This device was tested with an $\mathrm{Yb}$ high-power fiber-laser operating at $1080 \mathrm{~nm}$. The Gaussian profile of the fundamental transverse mode, $\mathrm{TEM}_{00}$, was photographed before and after passing through the OI.

As can be observed in Fig. 23, the circularity of the beam remained almost unchanged, showing a value very close to the ideal 1, and the insertion loss was found to be below $0.1 \mathrm{~dB}$. Additionally, the crystal damage threshold of $\left\{\mathrm{Tb}_{3}\right\}\left[\mathrm{Sc}_{2-x} \mathrm{Lu}_{x}\right]\left(\mathrm{Al}_{3}\right) \mathrm{O}_{12}$ was above that of $\mathrm{Tb}_{3} \mathrm{Ga}_{5} \mathrm{O}_{12}$, which broke at a continuous power of $300 \mathrm{~W}$ focused in a $100 \mu \mathrm{m}$ spot. These results further confirm the high optical quality of the $\left\{\mathrm{Tb}_{3}\right\}\left[\mathrm{Sc}_{2-x} \mathrm{Lu}_{x}\right]\left(\mathrm{Al}_{3}\right) \mathrm{O}_{12}$ crystal.

Although $\left\{\mathrm{Tb}_{3}\right\}\left[\mathrm{Sc}_{2-x} \mathrm{Lu}_{x}\right]\left(\mathrm{Al}_{3}\right) \mathrm{O}_{12}$ presents the superior properties in VIS-NIR region, it shows the strong 

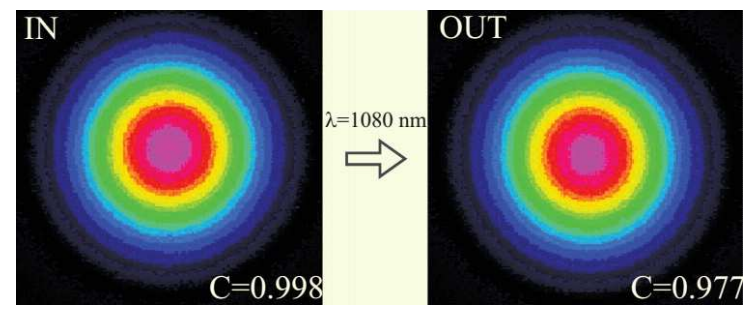

Fig. 23. Circularity, ratio between maximum and minimum diameter, of original and transmitted $1080 \mathrm{~nm}$ laser beams.

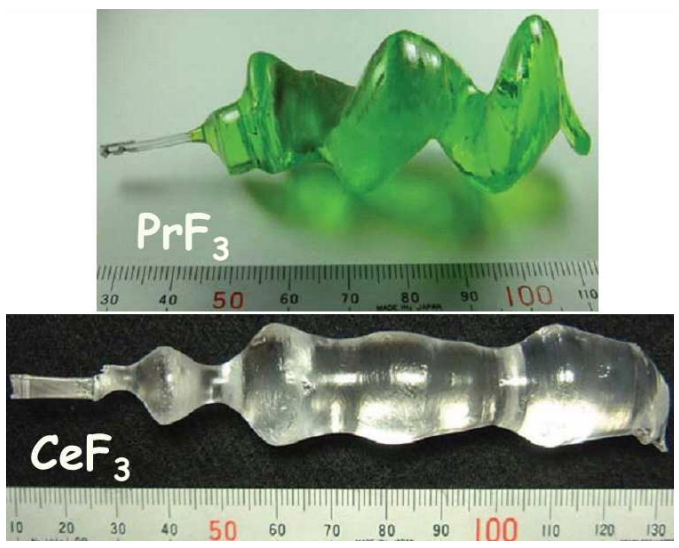

Fig. 24. $\mathrm{CeF}_{3}$ and $\mathrm{PrF}_{3}$ single crystals grown by the Czochralski technique.

absorption bands in the near UV and blue wavelength region. These are originated in the partially spin-allowed $4 f-4 f$ transitions of the MO active ion $\mathrm{Tb}^{3+}$, and therefore this crystal cannot be used at wavelengths neither below $400 \mathrm{~nm}$ nor at around $490 \mathrm{~nm}$. Consequently, there is a need to find FRs which can be used in non-covered UV and VIS wavelength regions. We have found that $\mathrm{CeF}_{3}$ and $\mathrm{PrF}_{3}$ single crystals are highly promising materials. Single crystals of these crystals were grown by the $\mathrm{Cz}$ technique (Fig. 24). $\mathrm{CeF}_{3}$ could grow rather straightly though $\mathrm{PrF}_{3}$ has shown the strong tendency of the spi-

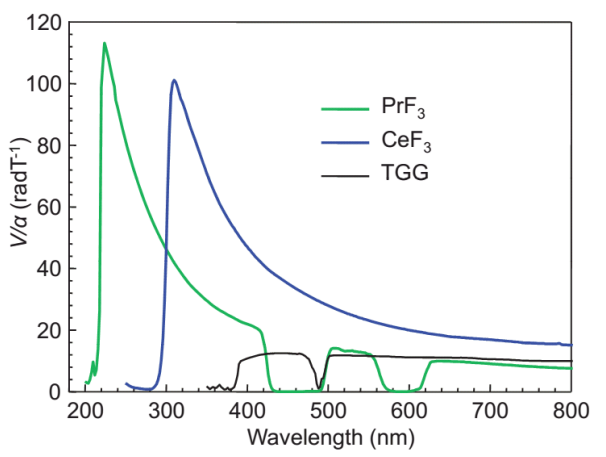

Fig. 25. Figure of merit of $\mathrm{CeF}_{3}$ and $\mathrm{PrF}_{3}$ in comparison to $\mathrm{Tb}_{3} \mathrm{Ga}_{5} \mathrm{O}_{12}$. ral growth $[35,36]$. FM of these crystals were measured and summarized in Fig. 25. These results indicate the high potential of $\mathrm{CeF}_{3}$ and $\mathrm{PrF}_{3}$ as optical isolators in the UV-visible, where at present there are no alternative candidates $[37,38]$.

\section{Conclusion}

In this article, we introduced the representative recent works of our group. The $\mathrm{Cz}$ and its derived techniques have been showing and will continue to show the marvelous importance for the science and industry. That is the reason why we have been and will keep working on these techniques. In this article, 4 kinds of our topics were reviewed.

2 inch size $\mathrm{BaMgF}_{4}$ single crystals without cracks have been grown by the $\mathrm{Cz}$ technique. The ferroelectric properties of bulk $\mathrm{BaMgF}_{4}$ have been measured by polarization hysteresis at different frequencies. The spontaneous polarization is $6.6 \mu \mathrm{C} / \mathrm{cm}^{2}$, while the coercive field varies between 4 and $10 \mathrm{kV} / \mathrm{cm}$ according to the IshibashiOrihara model. Periodical domain poling is achieved and evidenced by selective etching. SHG QPM has been obtained for Nd:YAG, Ti:sapphire and MOPA lasers. This is the first report on QPM using a PP ferroelectric fluoride, emitting in the ultraviolet wavelength region. The shortest period and shortest SHG wavelength realized so far is $6.6 \mu \mathrm{m}$ and $277 \mathrm{~nm}$, respectively. Present results show the high potential of $\mathrm{BaMgF}_{4}$ for the fabrication of UV/VUV frequency converters, in particular, for the ASSL generation at $193 \mathrm{~nm}$.

2 inch $\beta-\mathrm{Ga}_{2} \mathrm{O}_{3}$ single crystals were grown by the EFG technique. $\mathrm{GaN}$ was grown on the $\beta-\mathrm{Ga}_{2} \mathrm{O}_{3}$ substrate for the first time by the MOVPE technique. Very flat epitaxial growth of the wurtzite $c$-plane $\mathrm{GaN}$ was obtained on the $\beta-\mathrm{Ga}_{2} \mathrm{O}_{3}$ substrate after the deposition of a LT buffer layer. LED structure was fabricated on the substrate using a conductive buffer layer. Blue emission was successfully realized by the different packaging types of $\mathrm{InGaN} / \beta-\mathrm{Ga}_{2} \mathrm{O}_{3}$ LEDs with the vertical current injection. These results demonstrate the high potential of $\beta-\mathrm{Ga}_{2} \mathrm{O}_{3}$ as a new substrate for GaN based LED.

2 inch size $\mathrm{F}$-doped core-free $\mathrm{Y}_{3} \mathrm{Al}_{5} \mathrm{O}_{12}$ single crystals have been grown. These crystals confirmed several advantageous characteristics, such as improved transmittance at UV/VUV, large refractive index, and high uniformity of refractive indices. These advanced properties of F-doped core-free $\mathrm{Y}_{3} \mathrm{Al}_{5} \mathrm{O}_{12}$ toward the high potential as a new lens materials for industrial and optical facilities.

$\left\{\mathrm{Tb}_{3}\right\}\left[\mathrm{Sc}_{2-x} \mathrm{Lu}_{x}\right]\left(\mathrm{Al}_{3}\right) \mathrm{O}_{12} \quad$ single crystal has shown superior properties in comparison with $\mathrm{Tb}_{3} \mathrm{Ga}_{5} \mathrm{O}_{12}$ from any point of view related with OIs. $\left\{\mathrm{Tb}_{3}\right\}\left[\mathrm{Sc}_{2-x} \mathrm{Lu}_{x}\right]\left(\mathrm{Al}_{3}\right) \mathrm{O}_{12}$ has more favorable growth characteristics than $\mathrm{Tb}_{3} \mathrm{Ga}_{5} \mathrm{O}_{12}$, and a higher damage threshold. The increase of $20 \%$ in the Verdet constant is very significant, giving the possibility to reduce the intensity of the necessary magnetic fields specially in the IR. In the visible the FM of $\left\{\mathrm{Tb}_{3}\right\}\left[\mathrm{Sc}_{2-x} \mathrm{Lu}_{x}\right]\left(\mathrm{Al}_{3}\right) \mathrm{O}_{12}$ is much larger mainly due to the absence of absorpion losses 
that are present in $\mathrm{Tb}_{3} \mathrm{Ga}_{5} \mathrm{O}_{12}$. The measured features and device performance of $\left\{\mathrm{Tb}_{3}\right\}\left[\mathrm{Sc}_{2-x} \mathrm{Lu}_{x}\right]\left(\mathrm{Al}_{3}\right) \mathrm{O}_{12}$ clearly indicate that this crystal is industriallization mature. $\left\{\mathrm{Tb}_{3}\right\}\left[\mathrm{Sc}_{2-x} \mathrm{Lu}_{x}\right]\left(\mathrm{Al}_{3}\right) \mathrm{O}_{12}$ has a high potential to substitute commercial $\mathrm{Tb}_{3} \mathrm{Ga}_{5} \mathrm{O}_{12}$ crystals used in OIs in the IR region (below $1100 \mathrm{~nm}$ ), and more specially in the VIS. $\mathrm{CeF}_{3}$ is noteworthy for its higher transparency and FM in the whole VIS, as well as a superior FM in the regions 300 to $400 \mathrm{~nm}$ and around $490 \mathrm{~nm}$, where $\mathrm{Tb}_{3} \mathrm{Ga}_{5} \mathrm{O}_{12}$ is already opaque. Below the cutoff of $\mathrm{CeF}_{3}$ only $\mathrm{PrF}_{3}$ can be used. $\mathrm{PrF}_{3}$ possesses a superior FM in the UV region from 220 to $300 \mathrm{~nm}$. These results indicate that $\mathrm{CeF}_{3}$ has a high potential to be implemented in OIs operating in the near UV-VIS wavelength region, while $\operatorname{PrF}_{3}$ is the unique candidate for devices that should work in the UV, below $300 \mathrm{~nm}$.

\section{Acknowledgments}

We appreciate to introduce our work in the Year celebrating Professor Jan Czochralski. The work on $\mathrm{BaMgF}_{4}$ has been partially supported by the Industrial Technology Research Grant Program in 2007 from New Energy and Industrial Technology Development Organization (NEDO) of Japan. Authors would like to thank to Mr. K. Sumiya and Dr. H. Ishibashi of Hitachi Chemical Co., Ltd., Mr. T. Masui and Mr. K. Aoki of Koha Co. Ltd., Dr. Y. Kuwano of Dai-Ichi Dentsu Ltd., and Mr. A. Funaki, Mr. T. Hatanaka, and K. Naoe of Fujikura Ltd., for the great contributions on these works.

\section{References}

[1] T. Sasaki, Y. Mori, M. Yoshimura, Y.K. Yap, T. Kamimura, Mater. Sci. Eng. R 30, 1 (2000).

[2] J.A. Armstrong, N. Bloembergen, J. Duncan, P.S. Pershan, Phys. Rev. 127, 1918 (1962).

[3] M.M. Fejer, G.A. Magel, D.H. Jundt, R.L. Byer, IEEE J. Quant. Electron. 28, 2631 (1992).

[4] J.-P. Meyn, M.M. Fejer, Opt. Lett. 22, 1214 (1997).

[5] M. Eibschuetz, H.J. Guggenheim, S.H. Wemple, I. Camlibel, M. DiDomenico Jr., Phys. Lett. A 29, 409 (1969).

[6] S.C. Buchter, T.Y. Fan, V. Liberman, J.J. Zayhowski, M. Rothschild, Opt. Lett. 26, 1693 (2001).

[7] K. Shimamura, E.G. Víllora, K. Muramatsu, N. Ichinose, J. Cryst. Growth 275, 128 (2005).

[8] J.M. Rey, H. Bill, D. Lovy, H. Hagemann, J. Alloys Comp. 268, 60 (1998).

[9] N. Kodama, T. Hoshino, M. Yamaga, N. Ishizawa, K. Shimamura, T. Fukuda, J. Cryst. Growth 229, 492 (2001).

[10] T. Hayashi, M. Yoshihara, S. Ohmi, E. Tokumitsu, Appl. Surf. Sci. 117, 418 (1997).

[11] S. Sinharoy, H. Buhay, M.H. Francombe, W.J. Takei, N.J. Doyle, J.H. Fieger, D.R. Lampe, E. Stepke, J. Vac. Sci. Technol. A 9, 409 (1991).

[12] E.G. Víllora, K. Shimamura, K. Muramatsu, H. Kimura, K. Kitamura, N. Ichinose, J. Cryst. Growth 280, 145 (2005).

[13] K. Shimamura, E.G. Víllora, H. Zeng, M. Nakamura, S. Takekawa, K. Kitamura, Appl. Phys. Lett. 89, 232911 (2006).
[14] E.G. Víllora, K. Shimamura, F. Jing, A. Medvedev, S. Takekawa, K. Kitamura, Appl. Phys. Lett. 90 192909 (2007).

[15] M. Rolin, M. Clausier, Rev. Int. Hautes Temp. Refract. 4, 39 (1967).

[16] F. Jing, K. Shimamura, E.G. Víllora, A. Medvedev, K. Kitamura, K. Asai, A. Sato, J. Am. Ceram. Soc. 91, 296 (2008).

[17] K. Shimamura, E.G. Víllora, N. Ichinose, Adv. Electroceram. Mater. II, 221, 137 (2010).

[18] E.G. Víllora, K. Shimamura, K. Sumiya, H. Ishibashi, Opt. Expr. 17, 12362 (2009).

[19] K. Domen, A. Kuramata, R. Soegima, K. Horino, S. Kubota, T. Tanahashi, IEEE J. Sel. Topics Quantum Electron. 4, 490 (1998).

[20] L. Liu, J.H. Edgar, Mater. Sci. Eng. R 37, 61 (2002).

[21] H.H. Tippins, Phys. Rev. 140, A316 (1965).

[22] S. Geller, J. Chem. Phys. 33, 676 (1960).

[23] E.G. Víllora, K. Shimamura, Y. Yoshikawa, K. Aoki, N. Ichinose, J. Cryst. Growth 270, 420 (2004).

[24] K. Shimamura, E.G. Víllora, T. Ujiie, K. Aoki, Appl. Phys. Lett. 92, 201914 (2008).

[25] E.G. Víllora, K. Shimamura, T. Ujiie, K. Aoki, Appl. Phys. Lett. 92, 202118 (2008).

[26] E.G. Víllora, K. Shimamura, Y. Yoshikawa, K. Aoki, Appl. Phys. Lett. 92, 202120 (2008).

[27] K. Shimamura, E.G. Víllora, K. Domen, K. Yui, K. Aoki, N. Ichinose, Jpn. J. Appl. Phys., Exp. Lett. 44, L7 (2005).

[28] M. Geho, T. Sekijima, T. Fujii, J. Cryst. Growth 275, E663 (2005).

[29] C.B. Rubinstein, L.G. Van Uitert, W.H. Grodkiewicz, J. Appl. Phys. 35, 3069 (1964).

[30] S. Ganschow, D. Klimm, P. Reiche, R. Uecker, Cryst. Res. Technol. 34, 615 (1999).

[31] R.Z. Levitin, A.K. Zvezdin, M. von Ortenberg, V.V. Platonov, V.I. Plis, A.I. Popov, N. Puhlmann, O.M. Tatsenko, Phys. Solid State 44, 2107 (2002).

[32] R.C. Linares, Solid State Commun. 2, 229 (1964).

[33] K. Shimamura, T. Kito, E. Castel, A. Latynina, P. Molina, E.G. Víllora, M. Prakasam, P. Veber, J.P. Chaminade, A. Funaki, T. Hatanaka, K. Naoe, Cryst. Growth Des. 10, 3466 (2010).

[34] E.G. Víllora, P. Molina, M. Nakamura, K. Shimamura, T. Hatanaka, A. Funaki, K. Naoe, Appl. Phys. Lett. 99, 011111 (2011).

[35] K. Shimamura, E.G. Víllora, S. Nakakita, M. Nikl, N. Ichinose, J. Cryst. Growth 264, 208 (2004).

[36] E.G. Víllora, K. Shimamura, S. Nakakita, M. Nikl, N. Ichinose, Nucl. Instrum. Methods Phys. Res. A 537, 139 (2005).

[37] P. Molina, V. Vasyliev, E.G. Víllora, K. Shimamura, Opt. Expr. 19, 11786 (2011).

[38] V. Vasyliev, E.G. Víllora, M. Nakamura, Y. Sugahara, K. Shimamura, Opt. Expr. 20, 14460 (2012). 